\title{
FRUIT AND VEGETABLE CONSUMPTION AND CARDIOVASCULAR DISEASES AMONG JORDANIANS: A CASE-CONTROL STUDY
}

\author{
Reema F. Tayyem', Ala'a Al-Bakheit², Shatha S. Hammad', Abdel-Ellah Al-Shudifat ${ }^{3,4}$, Mohammed Azab, \\ Hiba Bawadi ${ }^{5}$ \\ ${ }^{1}$ Department of Nutrition and Food Technology, Faculty of Agriculture, University of Jordan, Amman, Jordan \\ ${ }^{2}$ Department of Nutrition and Food Processing, Faculty of Agricultural Technology, Al-Balqa Applied University, Al-Salt, Jordan \\ ${ }^{3}$ Faculty of Medicine, Hashemite University, Zarqa, Jordan \\ 4Prince Hamza Hospital, Amman, Jordan \\ ${ }^{5}$ College of Health Sciences, QU-Health, Qatar University, Doha, Qatar
}

\section{SUMMARY}

Objectives: Fruit and vegetable intake has been reported as one of the significant protective factors against the development of cardiovascular diseases (CVD). This study aimed to assess the possible preventive effect of fruit and vegetable consumption on developing CVD.

Methods: A total of 398 participants (205 cases and 193 controls) referred for elective coronary angiography with clinical suspicion of coronary artery disease to Prince Hamza Hospital in Amman were enrolled in this case-control study. Dietary data were collected separately from each patient using interview-based food frequency questionnaire.

Results: The findings of the present study revealed that a total consumption of 3 servings of vegetable per day decreased significantly the risk of CVD to about $54 \%(\mathrm{OR}=0.46,95 \% \mathrm{Cl}: 0.22-0.97, p=0.033)$. Consumption of banana was found to reduce the risk of CVD to about $44 \%$ and $62 \%$ when consuming 1-2 and 3-6 servings/week, respectively, with p-value for trend 0.004 . For the vegetables, the consumption of grape leaves and stuffed vegetables in general was significantly associated with lower risk of CVD. Increasing cauliflower consumption of 1-2 servings per week decreased CVD risk to about $37 \%(\mathrm{OR}=0.63,95 \% \mathrm{Cl}$ : $0.38-0.98)$. Consuming up to $3-6$ servings per week of mixed vegetables $(\mathrm{OR}=0.10,95 \%$ $\mathrm{Cl}: 0.01-0.83)$ and onion (OR=0.42, 95\% Cl: 0.22-0.80) revealed an inverse association with CVD development.

Conclusions: Adding to the present evidence, consumption of some fruits and vegetables could be considered as preventive factor against developing CVD. However, the association of consuming vegetables with preventing CVD was higher than the fruit consumption.

Key words: fruits, vegetables, cardiovascular disease, case-control study

Address for correspondence: Hiba Bawadi, College of Health Sciences, QU-Health, Qatar University, P.O. Box 2713, Doha, Qatar. E-mail: hbawadi@qu.edu.qa

https://doi.org/10.21101/cejph.a6149

\section{INTRODUCTION}

Cardiovascular diseases (CVD) represent number one leading cause of death in Jordan and worldwide $(1,2)$. The global number of CVD cases is expected to continue to increase. CVD development has been associated with many behavioural risk factors, such as smoking $(3,4)$, physical inactivity (4), obesity (4), and high fat diet (3). However, consuming a diet that is enriched with fruits and vegetables has been correlated with a lower risk of developing CVD (5-7).

Recently, the relationship between dietary fruits and vegetables and cardiovascular diseases has been an area of many researches. The evidence for a protective effect of fruit and vegetable consumption on CVD has been supported by several epidemiological studies and meta-analyses (8-10), as well as the findings of the cohort study European Prospective Investigation into Cancer and Nutrition (EPIC) (11).
Oyebode et al. (12) showed in their analysis that vegetable consumption was associated with reduced death rate from cardiovascular events for about $31 \%$ (HR $0.69 ; 95 \%$ CI 0.53 to 0.88 ); however, this relationship was not detected between dietary fruits and CVD mortality. Another study conducted on Japanese population (10) revealed that multivariate-adjusted hazard ratio (HR) for the highest versus the lowest quartile of the total of fruit and vegetable intake was 0.74 (95\% CI 0.61-0.91; p-value for trend $=0.003)$ for total CVD and 0.57 (95\% CI 0.37-0.87; p-value for trend $=0.109$ ) for coronary heart disease (CHD).

On the other hand, many studies documented different association between some individual items or groups of fruits or vegetables and CVD $(13,14)$. However, this is conflicting and inconsistent evidence (15). The most observed association has been reported for green leafy vegetable intake and reduction in CVD in the literature $(13,14)$. Therefore, the association between specific items of fruits and vegetables should be more investigated. 
In Jordan, non-communicable diseases are estimated to account for $76 \%$ of total deaths of which $35 \%$ of deaths are due to CVDs (16). Our study has been carried out in Jordan, a region of the world where relatively limited studies exploring the association between the intake of fruits and vegetables and the risk of CVD have been published. Since fruit and vegetable intake varies in different regions of the world, it is important to conduct national studies to detect the association between fruit and vegetable consumption and CVD. The results of this study may help in developing national and regional nutrition recommendations. Thus, the present study aimed at evaluating the fruit and vegetable intake as a protective factor against developing CVD.

\section{MATERIALS AND METHODS}

\section{Participants and Study Settings}

A case-control study was conducted between January and December 2015 to assess the association between vegetable and fruit intakes and CVD risk among Jordanians. Participants of the present study were enrolled conveniently from the catheterization section of the Cardiology Department of Prince Hamzah Hospital, a referral hospital in Amman. This study included a total of 398 participants (238 males and 160 females; 205 cases and 193 controls) who were referred by their physician for coronary angiography. The mean age of participants was 52years and their average BMI was $30.7 \mathrm{~kg} / \mathrm{m}^{2}$. Sample size was calculated so that the sample proportion would be within \pm 0.05 of the population proportion with a $95 \%$ confidence level and population of 500 persons. Inclusion criteria included: age $\geq 18$ years, Jordanian nationality, and being able to verbally communicate in Arabic. Participants who had critical illness, kidney disease, liver disease, gastrointestinal diseases, or were currently hospitalized were excluded. A ratio of unity was adopted to match the cases and controls based on age and gender. The Institutional Review Board Ethics Committee at Prince Hamzah Hospital reviewed and approved the proposal of this study; ethical approval number was 2015/011. Before signing the informed consent form, all participants were instructed to thoroughly read it where the researchers clarified any doubt the participants might have had.

All data were collected from patients eligible to be enrolled in the study on the day before the coronary angiography procedure. Upon the medical diagnosis, participants were classified in control or case group. Trained dietitians collected the required data during private interviews using valid questionnaires. The collected data included: personal, socio-demographic, dietary intake of fruits and vegetables, physical activity level, previous health issues, smoking status, and family history of CVD.

\section{Physical Activity Assessment}

The validated physical activity recall (PAR) questionnaire that was originally developed by Sallis et al. (17) was used in this study to evaluate the level of physical activity for each participant. Participants were asked to recall the usual time spent practicing physical activity over a period of one week prior undergoing coronary angiography.
7-Day PAR is a structured interview that depends on participant's recall of time spent engaging in physical activity over a seven-day period. The total physical activity metabolic equivalent (MET) minutes per week was obtained by summing the METs. Average MET for walking - 3.3METs, moderate activity - 4 METs, vigorous activity -8 , and extreme activity -10 . The score expressed as MET-min per week was calculated using this equation: (MET level $\times$ minutes of activity/days $\times$ days per week) then transfer into categorical analysis: inactive, minimally active, or health enhancing physical activity (HEPA) (17).

\section{Anthropometric Assessment}

All anthropometric measurements were taken for all participants by a trained dietitian in a private room. Each participant was weighed on a calibrated scale (Seca, Hamburg, Germany), barefoot and with minimal clothing, measurements were recorded for the nearest 0.1 kilogram. A portable measuring rod was used to measure the standing height for each participant and the readings were recorded to the nearest $0.1 \mathrm{~cm}$. Body mass index (BMI) was calculated by dividing the weight (in $\mathrm{kg}$ ) by height (in square meters). Waist circumference was measured using a standard tape to the nearest $1 \mathrm{~cm}$.

\section{Coronary Angiography}

Patients with signs of suspected heart attack who underwent coronary angiography to rule out this medical situation were enrolled in the study if they were eligible. X-ray images were taken by certified cardiologists using radiocontrast agent to help envisage the coronary arterial tree. The Seldinger technique was used to insert a catheter into the radial artery, and the tip was advanced to the aortic sinus cusp. The arterial lumen of the narrowed artery was compared to an adjacent normal artery in order to estimate the degree of obstruction within the target artery. Consistent with prior studies, coronary artery disease was defined as $\geq 20 \%$ stenosis of one or more coronary arteries $(18,19)$. Participants with no stenosis $(0 \%)$ were enrolled as controls.

\section{Dietary Assessment}

The assessment of dietary intake was achieved using a validated Arabic Food Frequency Questionnaire (FFQ) (20). The FFQ addressed the diet of the past 12 months which would reflect the seasonal variations of fruits and vegetables. Twenty-two types of vegetables (cooked leafy vegetable, raw leafy vegetable, grape leaves, cabbage, stuffed vegetable, cabbage salad, salad, carrot, green beans, corn, broccoli, cauliflower, mixed vegetables, onion, pickles, boiled potato, French fried potato, sweet potato, lettuce, tomato, sweet pepper, olive pickles) and 11 types of fruit (apple, pear, banana, dried fruits, peach, melon, watermelon, strawberry, orange, grapefruit, dates) and other fruits were selected in this study. Fruits and vegetables were compiled according to cultural influences (e.g. tomatoes and sweet peppers were categorized as vegetables, not fruits). Participants were asked to estimate the average frequency of consumption of a standardized serving of each food item consumed during the previous year. The frequency of consumption was classified into nine different categories $(\leq 1$ per month, 2-3 per month, 1-2 per week, 3-4 per week, 5-6 per 
week, 1 per day, 2-3 per day, 4-5 per day, or 6 per day). The consumption of fruits and vegetables was reclassified into daily and weekly types of consumption; each type was categorized into four levels of frequencies (daily: $\leq 1.0$ serving/day, 2 servings/day, 3 servings/day, $\geq 4$ servings/day; and weekly: $\leq 1$ serving/week, 1-2 servings/week, 3-6 servings/week, $\geq 1$ servings/ day). This reclassification was decided depending on the usual consumption of the participants. One serving of raw fruits or cooked vegetables was considered to be $1 / 2$ cup with some differences depending on the size of the fruits and vegetables. One cup was considered one serving for leafy vegetables. However, to assist the participants to precisely estimate the consumed portion size, food models and standard measuring tools were used. Knowing the frequency of consumption and the specified serving size for each food item, the average daily amount of each food item consumed by each participant was then calculated. Consumption of certain fruits and vegetables was not recorded because of the difficulty for some patients to estimate the eaten amount.

\section{Statistical Analyses}

IBM SPSS Statistics for Windows version 19.0 (IBM, Armonk, New York) was used to conduct all statistical analyses. For each type of consumption (i.e. daily and weekly), the category that represents the lowest level of consumption was set as the reference group.

Multinomial logistic regression was used to calculate odds ratios (ORs) and confidence intervals (CIs), and p-values for trend were calculated using linear regression. Before performing any statistical analysis, several factors were identified as potential confounders including age, sex, BMI, physical activity level, total energy intake, income level, education level, smoking, marital status, and family history of CVD. Chi-square test was used to detect the differences among categorical variables while analysis of variance (ANOVA) was used for continuous ones. The level of significance was set at $\mathrm{p}$-value $\leq 0.05$.

\section{RESULTS}

The distribution of standard risk factors for the study participants (males and females) is displayed by the daily number of consumed servings of fruits and vegetables (Table $1 \mathrm{a}$ and $1 \mathrm{~b}$ ). The mean age of participants was $56.2 \pm 0.55$ years for males and $57.2 \pm 0.82$ years for females, and the BMI mean was $29.1 \pm 0.33$ $\mathrm{kg} / \mathrm{m}^{2}$ for males and $31.9 \pm 0.40 \mathrm{~kg} / \mathrm{m}^{2}$ for females. A significantly higher consumption of fruits and vegetables was detected among older male participants (Table 1a). However, female participants did not show any difference in the consumption of fruits and vegetables according to age (Table $1 b$ ). Regarding the physical activity, a significant difference $(p<0.001)$ was detected in both metabolic equivalent level and the proportion of male participants practicing health enhancing physical activity. A higher level of physical activity practicing on daily basis was reported in male participants consuming 2 and $\geq 4$ servings of fruits/day. However, female participants showed a significant difference in METs as the consumption of fruits increased from less than 1 to more than 4 servings/day with $\mathrm{p}=0.014$. In addition, significant differences were observed in the level of education and the con- sumption of more fruits among females and vegetables among male participants.

Table 2 displays the CVD-adjusted ORs of cases and controls according to the number of consumed servings of fruits and vegetables. Overall, as the number of total vegetable servings increased to 3 servings per day, the incidence of CVD significantly decreased to about $54 \%(\mathrm{OR}=0.46,95 \%$ CI: $0.22-0.97$, $\mathrm{p}=0.033)$. Table 3 shows that consumption of banana can reduce the risk of CVD to about $44 \%$ and $62 \%$ when consuming $1-2$ and 3-6 servings/week, respectively, with p-value for trend 0.004 .

Regarding the vegetables (Table 4), the consumption of grape leaves and stuffed vegetables was significantly associated with lower risk of CVD when consuming 1-2 servings per week. Moreover, increasing cauliflower consumption to $1-2$ servings per week decreased CVD risk to about $37 \%(\mathrm{OR}=0.63,95 \% \mathrm{CI}$ : $0.38-0.98)$. Consuming mixed vegetables and onion was inversely associated with CVD development; as the number of consumed servings of the mixed vegetables increased up to 3-6 servings per week, CVD risk decreased to about $90 \%(\mathrm{OR}=0.10,95 \%$ CI: $0.01-0.83$ ). Additionally, the consumption of more than 1 serving of onion on daily basis showed a reduction of CVD risk with odds of 0.42 (95\% CI: $0.22-0.80)$.

On the other hand, no relationship was found for all other fruits (apples, pears, peach, melon, watermelon, strawberry, oranges, grapefruits, and dried fruits) and raw or cooked vegetables (tomato, salad, pickles, green beans, carrots, potato, lettuce, sweat peppers).

\section{DISCUSSION}

In the current study, we investigated the association between the intakes of the common fruits and vegetables consumed by the study participants and risk of developing CVD. In our study, the average age of both male and female participants who consumed 3-6 servings per day was in the range of 50-59 years and they were obese (BMI ranged from 31 to 34.8 ). The present study showed that the level of physical activity increased the number of servings consumed per day of either fruits or vegetables in both males and females, indicating that physically active participants were more likely following a healthy life style through increasing their daily number of servings of fruits and vegetables. Oppert et al. (21), in their study conducted on French adults, communicated that unhealthy lifestyle behaviours, particularly low level of physical activity, were inversely associated with the consumption of fruits and vegetables. Age and education adjusted leisure-time physical activity was associated with higher consumption rate of fruits $(\mathrm{OR}=2.05,95 \% \mathrm{CI}: 1.68-2.52$ and $\mathrm{OR}=1.90,95 \%$ CI: $1.41-2.05$ in men and women, respectively) and vegetables $(\mathrm{OR}=1.81,95 \% \mathrm{CI}: 1.48-2.21$ and $\mathrm{OR}=2.22,95 \% \mathrm{CI}: 1.66-2.97$ in men and women, respectively) (21). The same findings were also documented by Yu et al. who showed that participants with higher rate of fruit and vegetable consumption had higher physical activity levels (22). It could be also noticed that the daily number of fruit and vegetable servings consumed by both males and females who just got primary and secondary education was higher than that in other educational levels (22). This finding is contrary to most of the conducted studies examining the association between education level and the intake of fruits and vegetables $(22,23)$. These studies showed that as the level of education in- 


\begin{tabular}{|c|c|c|c|c|c|c|c|c|c|c|c|c|c|c|c|c|c|c|c|c|c|c|c|c|}
\hline & 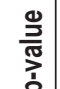 & & & $\begin{array}{l}\text { J } \\
0\end{array}$ & $\begin{array}{l}0 \\
0 \\
0 \\
0\end{array}$ & 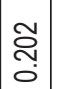 & $\stackrel{\stackrel{\mathscr{N}}{0}}{0}$ & 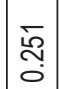 & $\left|\begin{array}{l}0 \\
0 \\
0 \\
0\end{array}\right|$ & $\frac{8}{0}$ & \multicolumn{6}{|c|}{ ठั } & \multicolumn{3}{|c|}{ 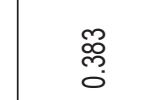 } & & \multicolumn{4}{|c|}{$\underset{\substack{\infty \\
\infty}}{\infty}$} \\
\hline $\begin{array}{l}\overline{\widehat{I}} \\
\frac{\mathrm{o}}{\mathrm{D}} \\
\frac{\mathrm{I}}{z}\end{array}$ & $\stackrel{+}{\mathbf{N}}$ & & $F$ & $\begin{array}{l}0 \\
\dot{+} \\
+1 \\
m \\
0 \\
0\end{array}$ & $\begin{array}{c}\stackrel{0}{i} \\
+1 \\
0 \\
\dot{m}\end{array}$ & 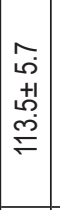 & 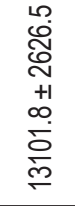 & 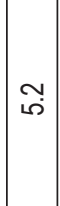 & $\mid \begin{array}{l}\dot{a} \\
\dot{o}\end{array}$ & 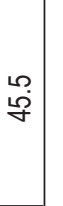 & O & $\because$ & $\begin{array}{l}\mathscr{8} \\
\tilde{\delta}\end{array}$ & $\because$ & $\begin{array}{l}\stackrel{N}{\infty} \\
\stackrel{\infty}{\infty}\end{array}$ & $\begin{array}{l}\widetilde{N} \\
\stackrel{\infty}{\infty}\end{array}$ & & $\stackrel{\circ}{\circ}$ & \begin{tabular}{c|c}
$N_{\infty}^{\infty}$ & $\infty$ \\
\end{tabular} & & 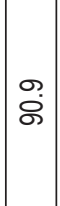 & $\dot{\sigma}$ & & $0^{\circ}$ \\
\hline 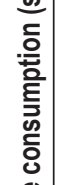 & $m$ & & 足 & $\begin{array}{l}0 \\
+1 \\
+1 \\
\stackrel{0}{0} \\
\dot{b}\end{array}$ & $\begin{array}{c}0 \\
\stackrel{-}{+1} \\
m \\
\stackrel{m}{m}\end{array}$ & 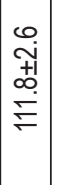 & 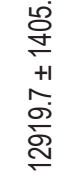 & $\stackrel{\infty}{\infty}$ & $\begin{array}{l}0 \\
0 \\
0 \\
0\end{array}$ & ָ̊ & $\begin{array}{l}0 \\
\infty\end{array}$ & $\underset{\sim}{\mathscr{\gamma}}$ & 岕 & $\stackrel{\stackrel{\rightleftarrows}{F}}{F}$ & $\stackrel{\circ}{\infty}$ & $\stackrel{\curvearrowright}{\sim}$ & & $\stackrel{s}{\mathrm{~N}}$ & Q & & 응 & $\because$ & & 8 \\
\hline 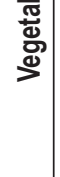 & $N$ & & $\widehat{\infty}$ & 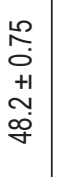 & $\begin{array}{c}\bar{\sigma} \\
\dot{0} \\
+1 \\
+ \\
\dot{N}\end{array}$ & $\begin{array}{c}0 \\
\text { i } \\
+1 \\
\stackrel{0}{0} \\
\stackrel{0}{0}\end{array}$ & $\begin{array}{l}\bar{\sigma} \\
\bar{\sigma} \\
+1 \\
\stackrel{\circ}{\circ} \\
\stackrel{\circ}{0} \\
\bar{\sigma}\end{array}$ & \begin{tabular}{|l|}
0 \\
$\dot{e}$
\end{tabular} & $\begin{array}{l}\stackrel{0}{\sim} \\
\stackrel{\sim}{\sim}\end{array}$ & 年 & in & 官 & $\approx$ & $\stackrel{m}{0}$ & $\stackrel{m}{\circ}$ & $\subsetneq$ & & 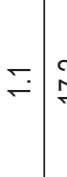 & \begin{tabular}{l|c}
$\mathbb{N}$ & $\mathbb{c}$ \\
\end{tabular} & & $\hat{\grave{a}}$ & 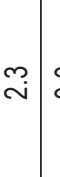 & & : \\
\hline & $\overline{\mathrm{v}}$ & & 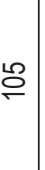 & 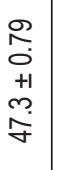 & 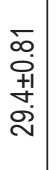 & 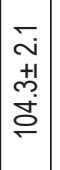 & 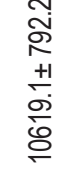 & 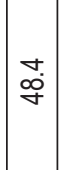 & $\begin{array}{l}10 \\
0 \\
0 \\
0\end{array}$ & $\widehat{\S}$ & $\stackrel{2}{\sim}$ & $\stackrel{m}{\underset{q}{*}}$ & $\overrightarrow{\tilde{m}}$ & 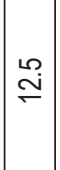 & $\widehat{\infty}$ & $\stackrel{\circ}{\circ}$ & & 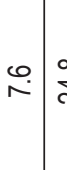 & 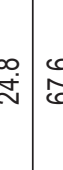 & & $\mid \begin{array}{l}n \\
\mathscr{8}\end{array}$ & $\stackrel{\infty}{\oplus^{\prime}}$ & & 8 \\
\hline & $\left|\begin{array}{l}0 \\
\frac{0}{5} \\
\underline{3} \\
\vdots\end{array}\right|$ & & & 范 & 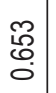 & $\frac{\pi}{5}$ & চे & \begin{tabular}{|l}
$\hat{\tilde{O}}$ \\
$\dot{\sigma}$
\end{tabular} & 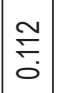 & ঙ্ল্ণ & \multicolumn{6}{|c|}{ 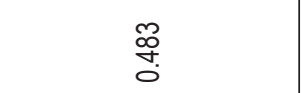 } & & & চे & & \multicolumn{4}{|c|}{ 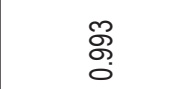 } \\
\hline 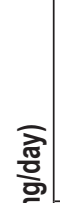 & $\begin{array}{l}\Delta \\
\Lambda 1\end{array}$ & & 0 & $\begin{array}{l}\bar{m} \\
+1 \\
+ \\
\dot{\delta}\end{array}$ & $\begin{array}{c}0 \\
\tilde{m} \\
+1 \\
\stackrel{\sim}{c} \\
\tilde{m}\end{array}$ & 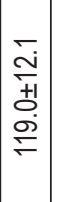 & 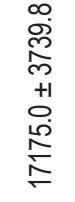 & $\stackrel{o}{\sim}$ & 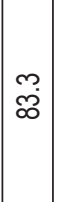 & $\underset{\infty}{\infty}$ & O & $\widehat{\widehat{\theta}}$ & is & $\mid \begin{array}{l}\hat{6} \\
\end{array}$ & $\hat{\underline{6}}$ & 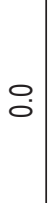 & & $\stackrel{\circ}{\circ}$ & $\because:$ & & 응 & $\because$ & & : \\
\hline 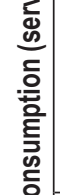 & $m$ & & 으 & $\begin{array}{l}\infty \\
\stackrel{0}{+1} \\
+1 \\
0 \\
\dot{0}\end{array}$ & 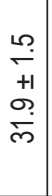 & $\mid \begin{array}{l}\infty \\
0 \\
0 \\
+1 \\
0 \\
0 \\
=\end{array}$ & 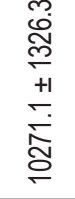 & \begin{tabular}{|l|}
$\mid$ \\
$\infty$ \\
$\infty$
\end{tabular} & ָ̃ & $\check{\check{\gamma}}$ & n? & 孞 & 离 & $m_{\infty}^{m}$ & $\begin{array}{l}L \\
0 \\
0\end{array}$ & 乃ై & & $\stackrel{\circ}{\circ}$ & $\stackrel{\substack{m \\
m}}{\infty}$ & & 응 & $\because$ & & : \\
\hline$\frac{\mathscr{m}}{5}$ & $N$ & & g & \begin{tabular}{c}
$m$ \\
$\stackrel{+}{+}$ \\
+1 \\
\multirow{F}{f}{}
\end{tabular} & $\begin{array}{l}0 \\
0 \\
+1 \\
+1 \\
0 \\
\stackrel{N}{D}\end{array}$ & $\left|\begin{array}{c}0 \\
+ \\
+1 \\
+1 \\
o \\
\hdashline\end{array}\right|$ & 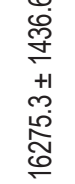 & \begin{tabular}{|l|}
$\stackrel{\circ}{\circ}$ \\
$\stackrel{\circ}{\circ}$
\end{tabular} & $\hat{\infty}$ & هి & 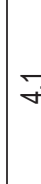 & $\begin{array}{l}\infty \\
\infty \\
\infty\end{array}$ & $\mid \begin{array}{l}0 \\
\stackrel{0}{\sim}\end{array}$ & $\underset{\infty}{\sim}$ & \begin{tabular}{|l}
0 \\
$\stackrel{0}{\circ}$
\end{tabular} & $\bar{\varnothing}$ & & $\widetilde{\sim}$ & $\stackrel{m}{\leftarrow} \mid \stackrel{N}{\sim}$ & & 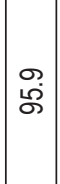 & $\check{F}$ & & 8 \\
\hline & $\overline{\mathbf{v}}$ & & 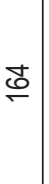 & 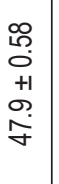 & $\begin{array}{l}0 \\
0 \\
0 \\
+1 \\
\infty \\
0 \\
\tilde{N}\end{array}$ & $\mid \begin{array}{l}\mid \\
\stackrel{0}{0} \\
+1 \\
m \\
\stackrel{0}{0} \\
\end{array}$ & 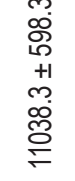 & $\mid \begin{array}{l}0 \\
\dot{8}\end{array}$ & 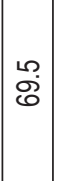 & ஜֶ & $g$ & $\begin{array}{l}0 \\
\dot{q}\end{array}$ & $\stackrel{\stackrel{0}{\sim}}{\stackrel{\sim}{\sim}}$ & 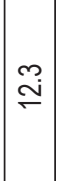 & $O_{\infty}^{\circ}$ & $\stackrel{\circ}{\circ}$ & & $\stackrel{\mathscr{g}}{+}$ & 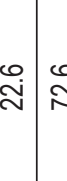 & & $\left|\begin{array}{l}0 \\
\dot{8}\end{array}\right|$ & 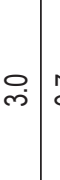 & & : \\
\hline & & 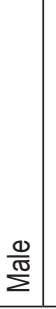 & $=$ & 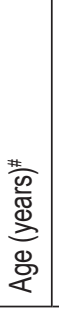 & 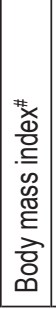 & 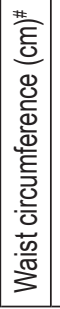 & 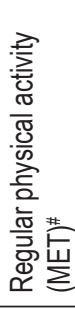 & 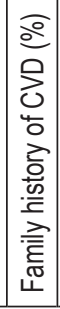 & 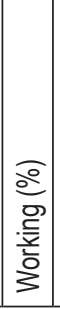 & 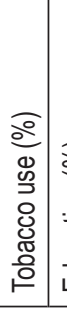 & 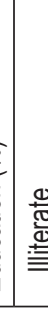 & 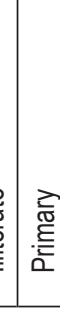 & 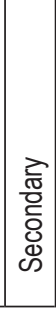 & 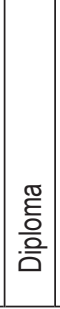 & 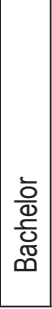 & 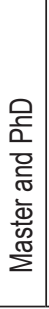 & 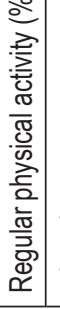 & 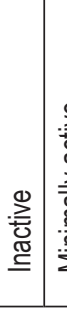 & 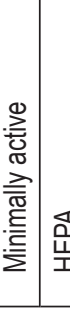 & 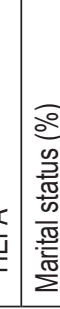 & 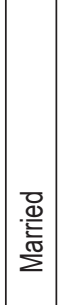 & 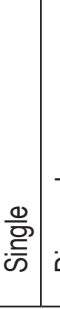 & & 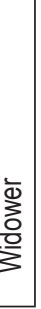 \\
\hline
\end{tabular}




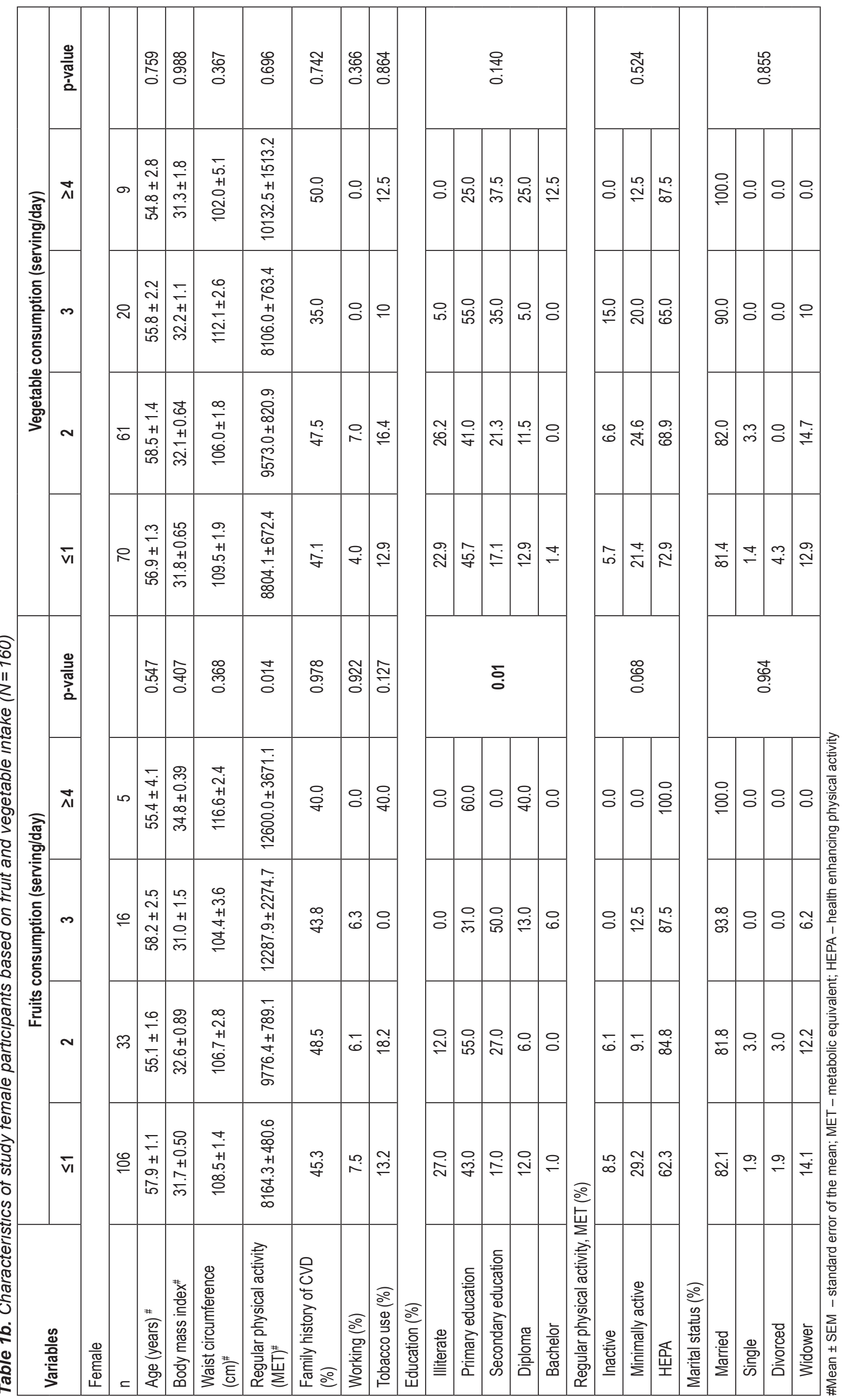


Table 2. Association between fruit and vegetable intake and CVD among Jordanians

\begin{tabular}{|c|c|c|c|c|}
\hline Variables & $\leq 1$ serving per day* & 2 servings per day & 3 servings per day & $\geq 4$ servings per day \\
\hline \multicolumn{5}{|l|}{ All fruits } \\
\hline Cases & 149 & 33 & 19 & 4 \\
\hline Control & 121 & 49 & 16 & 7 \\
\hline AOR $^{\#}(95 \% \mathrm{Cl})$ & 1 & $0.76(0.42-1.4)$ & $1.2(0.54-2.9)$ & $0.75(0.18-3.1)$ \\
\hline$p$-value & \multicolumn{4}{|c|}{0.293} \\
\hline \multicolumn{5}{|l|}{ All vegetables } \\
\hline Cases & 102 & 69 & 24 & 10 \\
\hline Control & 74 & 79 & 31 & 9 \\
\hline $\mathrm{AOR}^{\#}(95 \% \mathrm{Cl})$ & 1 & $0.61(0.36-1.1)$ & $0.46(0.22-0.97)$ & $1.1(0.34-3.6)$ \\
\hline$p$-value & \multicolumn{4}{|c|}{0.033} \\
\hline
\end{tabular}

* $\leq 1$ serving per day is considered as "reference group".

"AOR - adjusted odds ratio; $\mathrm{Cl}$ - confidence interval; AOR was adjusted for age, sex, total energy, physical activity, body mass index, education level, income level, smok-

ing, marital status, and family history of CVD.

Table 3. Association between intakes of common fruits consumed by study participants and CVD

\begin{tabular}{|c|c|c|c|c|}
\hline Variables & $\leq 1$ serving/week* & 1-2 servings/week & 3-6 servings/week & $\geq 1$ serving/day \\
\hline \multicolumn{5}{|l|}{ Apple } \\
\hline Cases & 80 & 78 & 18 & 26 \\
\hline Control & 66 & 74 & 22 & 30 \\
\hline $\mathrm{AOR}^{\#}(95 \% \mathrm{Cl})$ & 1 & $1.05(0.61-1.8)$ & $0.78(0.33-1.84)$ & $0.76(0.36-1.59)$ \\
\hline$p$-value & \multicolumn{4}{|c|}{0.580} \\
\hline \multicolumn{5}{|l|}{ Pear } \\
\hline Cases & 175 & 22 & 4 & 4 \\
\hline Control & 160 & 26 & 2 & 6 \\
\hline AOR $(95 \% \mathrm{Cl})$ & 1 & $0.86(0.42-1.79)$ & $5.4(0.49-60.7)$ & $0.56(0.13-2.5)$ \\
\hline$p$-value & \multicolumn{4}{|c|}{0.273} \\
\hline \multicolumn{5}{|l|}{ Banana } \\
\hline Cases & 86 & 80 & 14 & 25 \\
\hline Control & 56 & 87 & 25 & 26 \\
\hline AOR $(95 \% \mathrm{Cl})$ & 1 & $0.56(0.33-0.97)$ & $0.38(0.15-0.93)$ & $0.82(0.38-1.78)$ \\
\hline$p$-value & \multicolumn{4}{|c|}{0.004} \\
\hline \multicolumn{5}{|l|}{ Dried fruits } \\
\hline Cases & 198 & 3 & - & 4 \\
\hline Control & 189 & 4 & - & 1 \\
\hline AOR $(95 \% \mathrm{Cl})$ & 1 & $0.29(0.03-2.8)$ & - & $5.6(0.58-54.4)$ \\
\hline$p$-value & \multicolumn{4}{|c|}{0.935} \\
\hline \multicolumn{5}{|l|}{ Peach } \\
\hline Cases & 113 & 49 & 4 & 39 \\
\hline Control & 97 & 56 & 11 & 30 \\
\hline $\operatorname{AOR}(95 \% \mathrm{Cl})$ & 1 & $0.76(0.43-1.33)$ & $0.35(0.10-1.23)$ & $1.4(0.74-2.8)$ \\
\hline$p$-value & \multicolumn{4}{|c|}{0.139} \\
\hline \multicolumn{5}{|l|}{ Melon } \\
\hline Cases & 103 & 62 & 14 & 26 \\
\hline Control & 93 & 59 & 16 & 26 \\
\hline AOR $(95 \% \mathrm{Cl})$ & 1 & $1.1(0.63-1.85)$ & $0.92(0.38-2.2)$ & $1.2(0.57-2.3)$ \\
\hline$p$-value & \multicolumn{4}{|c|}{0.832} \\
\hline
\end{tabular}

Continued on the next page 
Continued from the previous page

\begin{tabular}{|c|c|c|c|c|}
\hline Variables & $\leq 1$ serving/week* & 1-2 servings/week & 3-6 servings/week & $\geq 1$ serving/day \\
\hline \multicolumn{5}{|l|}{ Watermelon } \\
\hline Cases & 90 & 55 & 20 & 40 \\
\hline Control & 63 & 64 & 21 & 46 \\
\hline AOR (95\% Cl) & 1 & $0.59(0.33-1.1)$ & $0.92(0.39-2.1)$ & $0.68(0.36-1.3)$ \\
\hline$p$-value & \multicolumn{4}{|c|}{0.085} \\
\hline \multicolumn{5}{|l|}{ Strawberry } \\
\hline Cases & 140 & 44 & 2 & 19 \\
\hline Control & 129 & 48 & 4 & 13 \\
\hline AOR (95\% Cl) & 1 & $0.90(0.51-1.6)$ & $0.22(0.02-2.2)$ & $1.6(0.68-4.0)$ \\
\hline$p$-value & \multicolumn{4}{|c|}{0.518} \\
\hline \multicolumn{5}{|l|}{ Orange } \\
\hline Cases & 88 & 45 & 14 & 58 \\
\hline Control & 67 & 53 & 10 & 61 \\
\hline $\mathrm{AOR}^{\#}(95 \% \mathrm{Cl})$ & 1 & $0.64(0.35-1.2)$ & $1.2(0.43-3.2)$ & $0.80(0.44-1.5)$ \\
\hline$p$-value & \multicolumn{4}{|c|}{0.060} \\
\hline \multicolumn{5}{|l|}{ Grapefruit } \\
\hline Cases & 182 & 15 & 2 & 6 \\
\hline Control & 166 & 19 & 2 & 7 \\
\hline AOR $(95 \% \mathrm{Cl})$ & 1 & $0.55(0.23-1.3)$ & $0.52(0.04-6.3)$ & $0.54(0.15-1.9)$ \\
\hline $\mathrm{p}$-value & \multicolumn{4}{|c|}{0.120} \\
\hline \multicolumn{5}{|l|}{ Dates } \\
\hline Cases & 83 & 49 & 19 & 53 \\
\hline Control & 83 & 30 & 13 & 62 \\
\hline AOR $(95 \% \mathrm{Cl})$ & 1 & $1.4(0.71-2.6)$ & $1.8(0.68-4.5)$ & $0.80(0.45-1.4)$ \\
\hline$p$-value & \multicolumn{4}{|c|}{0.301} \\
\hline \multicolumn{5}{|l|}{ Other fruits } \\
\hline Cases & 179 & 12 & 3 & 10 \\
\hline Control & 161 & 18 & 3 & 11 \\
\hline AOR $(95 \% \mathrm{Cl})$ & 1 & $0.90(0.38-2.13)$ & $1.0(0.999-1.00)$ & $1.1(0.41-2.7)$ \\
\hline$p$-value & \multicolumn{4}{|c|}{0.467} \\
\hline
\end{tabular}

* $\leq 1$ serving/week is considered as "reference group".

\#AOR - adjusted odds ratio; $\mathrm{Cl}$ - confidence interval. AOR was adjusted for age, sex, total energy, physical activity, body mass index, education level, income level, smoking, marital status, and family history of CVD.

creases the intake of fruits and vegetables increases as well (22, 23). This difference between our study results and other studies' results could be related to dissimilarities in cultures $(22,23)$. In Jordan, people with lower educational levels have more time to eat vegetables either raw or cooked, while people with higher level of education and occupations have limited time to consume healthy foods including vegetables and fruits. Most of Jordanians with higher education level depend of fast and ready-to-eat foods.

We found that banana consumption was significantly associated with reduced risk of developing CVD. Consuming 1-2 servings/week of banana significantly reduced the risk by $44 \%$ (AOR $=0.56$, CI: $0.33-0.97$, p-value 0.004$)$. This percentage was improved when the consumption was increased to 3-6 servings/ week of banana (AOR $=0.38, \mathrm{CI}: 0.15-0.93$, p-value 0.004 ). The effect of banana consumption on reducing the risk of CVD agreed with the findings of Hodgson et al. (24), but disagreed with those of Bondonno et al. (25). In addition, Oude et al. recently reported that banana consumption and blood pressure were inversely related in Asian adults (26); such association could be partially attributed to the mineral content of the banana, namely high potassium and magnesium contents (22). Additionally, soluble fiber content in banana could be attributed to CVD risk reduction. Recent scientific evidence supports that soluble fiber lowers cholesterol through increasing bile acid excretion and decreasing hepatic synthesis of cholesterol $(27,28)$. The reduction in serum cholesterol that is attributed to soluble fiber may range from $0.5 \%$ to $2 \%$ per gram of intake (27). On the other hand, regarding the association between the intakes of common vegetables consumed by the study participants and the risk of developing CVD, we found a trend of an inverse association between the risk 
Table 4. Association between intakes of common vegetable consumed by study participants and CVD

\begin{tabular}{|c|c|c|c|c|}
\hline Variables & $\leq 1$ serving/week* & 1-2 servings/week & 3-6 servings/week & $\geq 1$ serving/day \\
\hline \multicolumn{5}{|c|}{ Cooked leafy vegetable } \\
\hline Cases & 124 & 72 & 8 & 1 \\
\hline Control & 112 & 75 & 4 & 2 \\
\hline AOR* $(95 \% \mathrm{Cl})$ & 1 & $0.88(0.54-1.4)$ & $1.7(0.33-8.6)$ & $0.55(0.05-6.6)$ \\
\hline$p$-value & \multicolumn{4}{|c|}{0.746} \\
\hline \multicolumn{5}{|c|}{ Raw leafy vegetable } \\
\hline Cases & 62 & 75 & 12 & 55 \\
\hline Control & 45 & 79 & 23 & 47 \\
\hline AOR $(95 \% \mathrm{Cl})$ & 1 & $0.70(0.39-1.3)$ & $0.40(0.15-1.1)$ & $0.94(0.48-1.8)$ \\
\hline$p$-value & \multicolumn{4}{|c|}{0.161} \\
\hline \multicolumn{5}{|l|}{ Grape leaf } \\
\hline Cases & 184 & 20 & - & 1 \\
\hline Control & 168 & 26 & - & - \\
\hline AOR (95\% Cl) & 1 & $0.45(0.21-0.95)$ & - & - \\
\hline$p$-value & \multicolumn{4}{|c|}{0.198} \\
\hline \multicolumn{5}{|l|}{ Cabbage } \\
\hline Cases & 191 & 13 & 1 & - \\
\hline Control & 182 & 10 & - & 2 \\
\hline AOR $(95 \% \mathrm{Cl})$ & 1 & $1.0(0.41-2.6)$ & - & - \\
\hline$p$-value & \multicolumn{4}{|c|}{0.997} \\
\hline \multicolumn{5}{|l|}{ Stuffed vegetable } \\
\hline Cases & 189 & 16 & - & - \\
\hline Control & 170 & 24 & - & - \\
\hline AOR (95\% Cl) & 1 & $0.34(0.14-0.82)$ & - & - \\
\hline$p$-value & \multicolumn{4}{|c|}{0.073} \\
\hline \multicolumn{5}{|l|}{ Cabbage salad } \\
\hline Cases & 191 & 13 & 1 & - \\
\hline Control & 182 & 10 & - & 2 \\
\hline AOR $(95 \% \mathrm{Cl})$ & 1 & $1.0(0.41-2.6)$ & - & - \\
\hline$p$-value & \multicolumn{4}{|c|}{0.997} \\
\hline \multicolumn{5}{|l|}{ Salad } \\
\hline Cases & 24 & 96 & 40 & 43 \\
\hline Control & 24 & 82 & 31 & 57 \\
\hline AOR (95\% Cl) & 1 & $1.2(0.59-2.6)$ & $1.5(0.64-3.7)$ & $0.80(0.35-1.8)$ \\
\hline$p$-value & \multicolumn{4}{|c|}{0.161} \\
\hline \multicolumn{5}{|l|}{ Carrot } \\
\hline Cases & 123 & 59 & 9 & 14 \\
\hline Control & 118 & 55 & 6 & 15 \\
\hline AOR (95\% Cl) & 1 & $0.97(0.57-1.6)$ & $1.4(0.42-4.8)$ & $1.1(0.44-2.7)$ \\
\hline $\mathrm{p}$-value & \multicolumn{4}{|c|}{0.767} \\
\hline \multicolumn{5}{|l|}{ Broccoli } \\
\hline Cases & 198 & 5 & 2 & - \\
\hline Control & 186 & 8 & - & - \\
\hline AOR $(95 \% \mathrm{Cl})$ & 1 & $0.47(0.13-1.8)$ & - & - \\
\hline$p$-value & \multicolumn{4}{|c|}{0.249} \\
\hline
\end{tabular}

Continued on the next page 
Continued from the previous page

\begin{tabular}{|c|c|c|c|c|}
\hline \multicolumn{5}{|l|}{ Cauliflower } \\
\hline Cases & 132 & 60 & 7 & 6 \\
\hline Control & 115 & 72 & 3 & 4 \\
\hline AOR $(95 \% \mathrm{Cl})$ & 1 & $0.63(0.38-0.98)$ & $1.4(0.30-6.1)$ & $1.3(0.32-5.6)$ \\
\hline$p$-value & \multicolumn{4}{|c|}{0.139} \\
\hline \multicolumn{5}{|l|}{ Mixed vegetables } \\
\hline Cases & 129 & 72 & 1 & 3 \\
\hline Control & 117 & 57 & 10 & 10 \\
\hline AOR $(95 \% \mathrm{Cl})$ & 1 & $1.0(0.62-1.7)$ & $0.10(0.01-0.83)$ & $0.35(0.09-1.4)$ \\
\hline$p$-value & \multicolumn{4}{|c|}{0.752} \\
\hline \multicolumn{5}{|l|}{ Onion } \\
\hline Cases & 49 & 67 & 19 & 69 \\
\hline Control & 36 & 53 & 12 & 90 \\
\hline $\mathrm{AOR}(95 \% \mathrm{Cl})$ & 1 & $0.91(0.48-1.7)$ & $0.79(0.31-2.0)$ & $0.42(0.22-0.80)$ \\
\hline$p$-value & 0.758 & & & \\
\hline \multicolumn{5}{|l|}{ Pickles } \\
\hline Cases & 113 & 55 & 5 & 31 \\
\hline Control & 104 & 48 & 4 & 35 \\
\hline $\mathrm{AOR}(95 \% \mathrm{Cl})$ & 1 & $1.1(0.61-1.8)$ & $1.8(0.34-9.6)$ & $1.0(0.52-1.9)$ \\
\hline $\mathrm{p}$-value & \multicolumn{4}{|c|}{0.984} \\
\hline
\end{tabular}

* $\leq 1$ serving/week is considered as "reference group".

"AOR - adjusted odds ratio, $\mathrm{Cl}$ - confidence interval. AOR was adjusted for age, sex, total energy, physical activity, body mass index, education level, income level, smoking, marital status, and family history of CVD.

of developing CVD and consuming 1-2 servings per week of grape leaves, stuffed vegetables and cauliflower $(\mathrm{AOR}=0.45, \mathrm{CI}$ : $0.21-0.95 ; \mathrm{AOR}=0.34, \mathrm{CI}: 0.14-0.82 ; \mathrm{AOR}=0.63, \mathrm{CI}: 0.38-1.0$, respectively). The consumption of cruciferous vegetables, including broccoli and cauliflower, has been linked to reduced risk of developing cancer (29) and CVD (30). In a study by Sesso et al. (31), broccoli consumption was correlated with non-significant reductions in CVD risk. In the present study, we did not find a significant association between broccoli consumption and reduced risk of CVD. The lack of significance can be referred to the low number of cases who consumed the broccoli in our study compared to the other types of vegetables investigated in the study. This low number is attributed to the fact that broccoli is not very common in our culture compared to cauliflower, the other member of the cruciferous vegetables, which is very popular in our country and is part of many local dishes. Consuming 1-2 servings per week of cauliflower is associated with $37 \%$ reduction in the risk of developing CVD ( $\mathrm{AOR}=0.63$, CI: $0.38-0.98)$. It is interesting that the consumption of mixed vegetables was associated with the highest reduction in the risk of developing CVD. Mixed vegetables reduced the risk by $90 \%(\mathrm{AOR}=0.10$, CI: 0.01-0.83), however, no significant association was detected for their consumption trend. The beneficial effect of increasing consumption of vegetables against CVD can be attributed to the fact that vegetables generally are not only rich in antioxidant and anti-inflammatory compounds, but also rich in dietary fibers, such as cellulose, hemicellulose and pectin as well as lignans (32). It has been shown that a diet rich in lignans is associated with reduced risk of CVD (33). The bioactive compounds of lignans have been found to act as a protective effect against CVD through decreasing the levels of glucose and lipid, reducing blood pressure, and decreasing oxidative stress and inflammation (34).

The lack of significance between consumption of fruits and CVD can be attributed to the low number of cases that consume fruits in general. This is because of the cost and availability of fruit. The latter two factors are important factors that determine the consumption patterns. In Jordan, fruits are available, however, the cost is considered relatively high, especially that Jordan is one of the low to middle income countries.

\section{Study Strength and Limitations}

The limitations of this study include the fact that the dietary questionnaire recalled dietary pattern of only one year, which is a considerable short duration as compared to the pathophysiology of CVD. However, the accuracy of recall ability could be diminished with lengthier periods. Additionally, we believe that the recall period of one year (used in this study) is very likely reflective of the previous years, as most of the participants indicated a constant dietary pattern during the last 5 years. Thus, the associations, revealed in this study, between fruit and vegetable consumption and CVD may have been developing for several years. On the other hand, the main strength of this study is the use of a validated Arabic FFQ that was modified to reflect food consumption patterns in Arab countries, especially Jordan. The use of standardized food models and measuring tools to estimate portion sizes is another point that can improve the accuracy of the collected data. 


\section{CONCLUSION}

The findings of our study in general support recommendations to increase consumption of fruits, especially banana, and vegetables as protective agents against CVD and promote overall longevity. Total vegetable consumption was significantly related to a lower risk of developing CVD. However, there were differences in the effect of consuming individual vegetables on the risk of CVD. Grape leaves, stuffed vegetables, broccoli, cauliflower, raw leafy vegetables, mixed vegetables, onion, and lettuce, all reduced the risk, although a significant association was not detected. On the other hand, banana consumption was inversely associated with CVD. More studies are needed to further explore our results, especially the correlation of cruciferous vegetables and CVD.

\section{Conflict of Interests}

None declared

\section{Acknowledgements}

We thank the patients who participated in the study, and the hospital management for facilitating the data collection and all other aspects of this research.

\section{Adherence to Ethical Standards}

This study was conducted according to the guidelines laid down in the Declaration of Helsinki and all procedures involving research study participants were approved by the Institutional Review Board (IRB) at Prince Hamza Hospital. Written informed consent was obtained from all subjects/patients. IRB Approval number was MH/32/2285.

\section{Authors' Contribution}

RT, AES and MA conceived designed and supervised the study. AES and MA oversaw patient recruitment. RT and SH were responsible for analysis and interpretation of the data. RT, AA, SH and HB drafted the manuscript. All authors critically reviewed the manuscript and approved the final version.

\section{REFERENCES}

1. World Health Organization. Monitoring health for the SDGs: sustainable development goals. Geneva: WHO; 2016.

2. Roth GA, Huffman MD, Moran AE, Feigin V, Mensah GA, Naghavi M, et al. Global and regional patterns in cardiovascular mortality from 1990 to 2013. Circulation. 2015 Oct 27;132(17):1667-78.

3. Bhatnagar A. Environmental determinants of cardiovascular disease. Circ Res. 2017;121(2):162-80.

4. Dhungana RR, Thapa P, Devkota S, Banik PC, Gurung Y, Mumu SJ, et al. Prevalence of cardiovascular disease risk factors: A community-based cross-sectional study in a peri-urban community of Kathmandu, Nepal. Indian Heart J. 2018 Dec;70 Suppl 3:S20-7.

5. Alissa EM, Ferns GA. Dietary fruits and vegetables and cardiovascular diseases risk. Crit Rev Food Sci Nutr. 2017;57(9):1950-62.

6. Mirmiran P, Noori N, Zavareh MB, Azizi F. Fruit and vegetable consumption and risk factors for cardiovascular disease. Metabolism. 2009;58(4):460-8.

7. Zhan J, Liu YJ, Cai LB, Xu FR, Xie T, He QQ. Fruit and vegetable consumption and risk of cardiovascular disease: a meta-analysis of prospective cohort studies. Crit Rev Food Sci Nutr. 2017:57(8):1650-63.

8. Buil-Cosiales P, Toledo E, Salas-Salvadó J, Zazpe I, Farràs M, BasterraGortari FJ, et al.; PREDIMED investigators. Association between dietary fibre intake and fruit, vegetable or whole-grain consumption and the risk of CVD: results from the PREvención con DIeta MEDiterránea (PREDIMED) trial. Br J Nutr. 2016 Aug;116(3):534-46.
9. He FJ, Nowson CA, Lucas M, MacGregor GA. Increased consumption of fruit and vegetables is related to a reduced risk of coronary heart disease: meta-analysis of cohort studies. J Hum Hypertens. 2007 Sep;21(9):71728.

10. Okuda N, Miura K, Okayama A, Okamura T, Abbott RD, Nishi N, et al.; NIPPON DATA80 Research Group. Fruit and vegetable intake and mortality from cardiovascular disease in Japan: a 24-year follow-up of the NIPPON DATA80 Study. Eur J Clin Nutr. 2015 Apr;69(4):482-8.

11. Crowe FL, Roddam AW, Key TJ, Appleby PN, Overvad K, Jakobsen MU, et al.; European Prospective Investigation into Cancer and Nutrition (EPIC)-Heart Study Collaborators. Fruit and vegetable intake and mortality from ischaemic heart disease: results from the European Prospective Investigation into Cancer and Nutrition (EPIC)-Heart study. Eur Heart J. 2011 May;32(10):1235-43.

12. Oyebode O, Gordon-Dseagu V, Walker A, Mindell JS. Fruit and vegetable consumption and all-cause, cancer and CVD mortality: analysis of Health Survey for England data. J Epidemiol Community Health. 2014 Sep;68(9):856-62.

13. Bhupathiraju SN, Wedick NM, Pan A, Manson JE, Rexrode KM, Willett WC, et al. Quantity and variety in fruit and vegetable intake and risk of coronary heart disease. Am J Clin Nutr. 2013 Dec;98(6):1514-23.

14. Hu D, Huang J, Wang Y, Zhang D, Qu Y. Fruits and vegetables consumption and risk of stroke: a meta-analysis of prospective cohort studies. Stroke. 2014 Jun;45(6):1613-9.

15. Oude Griep LM, Verschuren WM, Kromhout D, Ocké MC, Geleijnse JM. Colors of fruit and vegetables and 10-year incidence of stroke. Stroke. 2011 Nov;42(11):3190-5.

16. World Health Organization. Noncommunicable Diseases (NCD) Country Profiles. Geneva: WHO; 2014.

17. Sallis JF, Haskell WL, Wood PD, Fortmann SP, Rogers T, Blair SN, et al. Physical activity assessment methodology in the Five-City Project. Am J Epidemiol. 1985;121(1):91-106.

18. Bradley SM, Maddox TM, Stanislawski MA, O'Donnell CI, Grunwald GK, Tsai TT, et al. Normal coronary rates for elective angiography in the Veterans Affairs Healthcare System: insights from the VACART program (veterans affairs clinical assessment reporting and tracking). J Am Coll Cardiol. 2014,63(5):417-26.

19. Maddox TM, Stanislawski MA, Grunwald GK, Bradley SM, Ho PM, Tsai TT, et al. Nonobstructive coronary artery disease and risk of myocardial infarction. JAMA. 2014;312(17):1754-63

20. Tayyem RF, Abu-Mweis SS, Bawadi HA, Agraib L, Bani-Hani K. Validation of a food frequency questionnaire to assess macronutrient and micronutrient intake among Jordanians. J Acad Nutr Diet. 2014;114(7):1046-52.

21. Oppert JM, Thomas F, Charles MA, Benetos A, Basdevant A, Simon C. Leisure-time and occupational physical activity in relation to cardiovascular risk factors and eating habits in French adults. Public Health Nutr. 2006;9(6):746-54

22. Yu D, Zhang X, Gao YT, Li H, Yang G, Huang J, et al. Fruit and vegetable intake and risk of CHD: results from prospective cohort studies of Chinese adults in Shanghai. Br J Nutr. 2014;111(2):353-62.

23. Affret A, Severi G, Dow C, Mancini FR, Rey G, Delpierre C, et al. Socio-economic factors associated with an increase in fruit and vegetable consumption: a 12-year study in women from the E3N-EPIC study. Public Health Nutr. 2018;21(4):740-55.

24. Hodgson JM, Prince RL, Woodman RJ, Bondonno CP, Ivey KL, Bondonno $\mathrm{N}$, et al. Apple intake is inversely associated with all-cause and disease-specific mortality in elderly women. Br J Nutr 2016;115(5):860-7.

25. Bondonno NP, Lewis JR, Prince RL, Lim WH, Wong G, Schousboe JT, et al. Fruit intake and abdominal aortic calcification in elderly women: a prospective cohort study. Nutrients. 2016;8(3):159-71.

26. Oude Griep LM, Stamler J, Chan Q, Van Horn L, Steffen LM, Miura $\mathrm{K}$, et al. Association of raw fruit and fruit juice consumption with blood pressure: the INTERMAP Study. Am J Clin Nutr 2013;97(5):1083-91.

27. Rimm EB, Ascherio A, Giovannucci E, Spiegelman D, Stampfer MJ, Willett WC. Vegetable, fruit, and cereal fiber intake and risk of coronary heart disease among men. JAMA. 1996;275(6):447-51.

28. Satija A, Hu FB. Cardiovascular benefits of dietary fiber. Curr Atheroscler Rep. 2012;14(6):505-14.

29. Armah CN, Traka MH, Dainty JR, Defernez M, Janssens A, Leung W, et al. A diet rich in high-glucoraphanin broccoli interacts with genotype to reduce discordance in plasma metabolite profiles by modulating mitochondrial function. Am J Clin Nutr. 2013;98(3):712-22.

30. Armah CN, Traka MH, Dainty JR, Doleman JF, Potter JF, Mithen RF. Effect of a high glucoraphanin broccoli diet on blood pressure and the 
cardiovascular risk profile of an at risk group: a randomised controlled study. J Hypertens. 2012 Sep;30 Suppl 1:e123. doi: 10.1097/01. hjh.0000420271.89131.02.

31. Sesso HD, Gaziano JM, Liu S, Buring JE. Flavonoid intake and the risk of cardiovascular disease in women. Am J Clin Nutr. 2003;77(6):1400-8.

32. Slavin JL, Lloyd B. Health benefits of fruits and vegetables. Adv Nutr. $2012 \mathrm{Jul} ; 3(4): 506-16$.

33. Grosso G, Micek A, Godos J, Pajak A, Sciacca S, Galvano F, et al. Dietary flavonoid and lignan intake and mortality in prospective cohort studies: systematic review and dose-response meta-analysis. Am J Epidemiol. 2017 Jun 15;185(12):1304-16

34. Adolphe JL, Whiting SJ, Juurlink BH, Thorpe LU, Alcorn J. Health effects with consumption of the flax lignan secoisolariciresinol diglucoside. $\mathrm{Br}$ J Nutr. 2010 Apr;103(7):929-38

Received February 21, 2020 Accepted in revised form July 31, 2020 